\title{
A Benign Ovarian Tumour developing an Endometrial Cancer? Sertoliform Ovarian Cystoadenoma getting together with an Endometrioid Adenocarcinoma
}

Presented at 1st International Online BioMedical Conference

J. Martinez-Mas ${ }^{1}$, A. Bueno-Crespo ${ }^{2}$, P. J. Garcia-Laencina ${ }^{3}$, J.P. Martinez-Cendan ${ }^{1,4}$, A. Isaac-Montero ${ }^{5}$, A. B. Garcia-Nicolas ${ }^{1}$, M. Remezal-Solano ${ }^{1,4}$

\section{Abstract}

Introduction: Sertoli cells tumours are neoplasms with a very low incidence, being sertoliform cystoadenomae extremely unusual. Its first description was made on 1982 by Young and Roth, with very few cases published after them. This is a neoplasm only described on postmenopausal women, with an average age of presentation of 68 year old, and they could suffer virilization symptoms in different degrees. Histologically, it is a well differentiated neoplasm, with a low malignancy degree, and good prognosis if it is confined to ovaries. In other way, the finding of this ovarian tumour getting together with an endometrioid adenocarcinoma is an extremely rare case.

Medical Case: A 66 year old woman, who attended our office relating postmenopausal metrorrhage, is presented. The patient had a medical history of diabetes mellitus type II, arterial hypertension, dyslipidemia, liver steatosis, glaucoma and appendectomy. She got three deliveries and had her menopause at the age of 53.

An outpatient hysteroscopy was carried on, finding three endometrial polyps, two of them appeared as normal, and the bigger one had a glandular appearance with atypical vascularization, taking biopsy of it that was informed as endometrioid type adenocarcinoma with mucus-secreting pattern.

Ultrasoud scanning, magnetic resonance and serum Ca 125 were carried on, finding a $2,5 \mathrm{~cm}$ left ovarian nodule with negative $\mathrm{Ca}$ 125.
1 Obstetrics and Gynaecology Service. Santa Lucía University Hospital, Cartagena, Murcia, Spain.

2 Assistant Professor at Department of Computer Science, Catholic University of Murcia (UCAM), Murcia, Spain.

3 Associate professor at Sciences and Informatics Department, University Centre of Defence at the Spanish Air Force Academy, Murcia, Spain.

4 Senior lecturer at Obstetrics and Gynaecology Department, Catholic University of Murcia (UCAM), Murcia, Spain.

5 Pathologic Anatomy Department. Santa Lucía University Hospital, Cartagena, Murcia, Spain.

\section{Contact information:}

José Martínez-Más.

Address: Obstetrics and Gynecology Service. Santa Lucía University Hospital, Calle Mezquita s/n, Paraje Los Arcos, 30202, Cartagena, Spain.

Tel: 0034699877148

झjomartmas@gmail.com 
An abdominal total hysterectomy with double adnexectomy, was carried on, with intraoperative biopsy, informed as a borderline tumour. Due to this finding, the operation was completed with omentectomy, lymphadenectomy and peritoneal washing.

Last histological analysis identifies the ovarian tumour as sertoliform adenoma from rete ovarii, with hepatocyte multifocal metaplasia. This tumour is suspected of being estrogenic functioning one, probably was the inductor of low degree and moderatedly differentiated G2 endometrioid adenocarcinoma. There was no lymphatic or omental metastases. FIGO staging IA, TNM staging T1aNOMO.

Conclusions: Sertoliform cystoadenoma is a very rare finding, with only few cases reported. It could be an estrogenic functioning tumour and due to this characteristic could induce endometrial hyperplasia, and at last, could be the reason for appearance of low malignancy degree endometrial neoplasms.

\author{
Keywords \\ Sertoliform Cystoadenoma; \\ Endometrioid Adenocarcinoma \\ Induction; \\ Estrogenic Overproduction.
}

\section{Introduction}

Sertoli cells tumours are neoplasms with a very low incidence, being sertoliform cystoadenoma extremely unusual. The first description of this tumor was made on 1982 by Young and Roth [1,2], with very few cases published after them. Sertoliform cystoadenoma is a neoplasm described only on postmenopausal women [3], with an average age of presentation of 68 year old, and has been related to virilization symptoms in different degrees, abdominal swelling, acute abdominal symptoms and postmenopausal metrorrhage [4]. Histologically, it is a well differentiated neoplasm, with a low malignancy degree, and good prognosis if it is confined to ovaries [5]. In other way, the finding of this ovarian tumour getting together with an endometrioid adenocarcinoma is an extremely rare case [6].

It has been described that postmenopausal women with epithelial ovarian tumours would be able to develop a potential to produce sex steroid hormones, mainly estrogens [7-10]. However, the incidence of this overproduction still remains con- troversal [11]. Moreover, the developing of endometrial endometrioid adenocarcinoma could be related with the estrogenic ovarian production from an ovarian tumour or could be just a synchronic presentation of both tumours.

\section{Medical Case}

A 66 year old woman, who attended our office relating postmenopausal metrorrhage, is presented. The patient had a medical history of diabetes mellitus type II, arterial hypertension, dyslipidemia, liver steatosis, glaucoma and appendectomy. She got three deliveries and had her menopause at the age of 53 .

An outpatient hysteroscopy was carried on, finding three endometrial polyps, two of them appeared as normal, and the bigger one had a glandular appearance with atypical vascularization. The biopsy of this polyp was informed as endometrioid type adenocarcinoma with mucus-secreting pattern. 
Ultrasoud scanning found an $2.5 \mathrm{~cm}$. adnexal left nodule with heterogeneous ultrasonic pattern, and endometrial $11 \mathrm{~mm}$ thickening. Magnetic Resonance found that the adnexal left nodule, with heterogeneous signal pattern and significant contrast agent captation, was suggestive of malignancy. Serum Ca125 detected was $5 \mathrm{Ul} / \mathrm{ml}$.

An abdominal total hysterectomy with double adnexectomy was carried on, with intraoperative biopsy, informed as a borderline tumour. Due to this finding, the surgical intervention was completed with omentectomy, pelvic lymphadenectomy and peritoneal washing. (Figure 1 and 2).

Figure 1: Macroscopic presentation of left ovary.

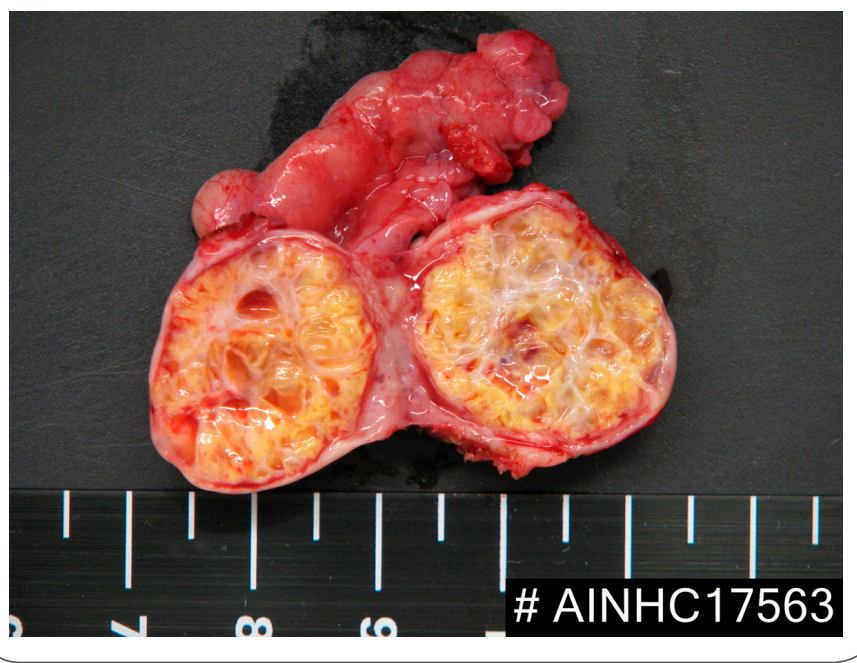

Figure 2: Macroscopic presentation of hysterectomy specimen.

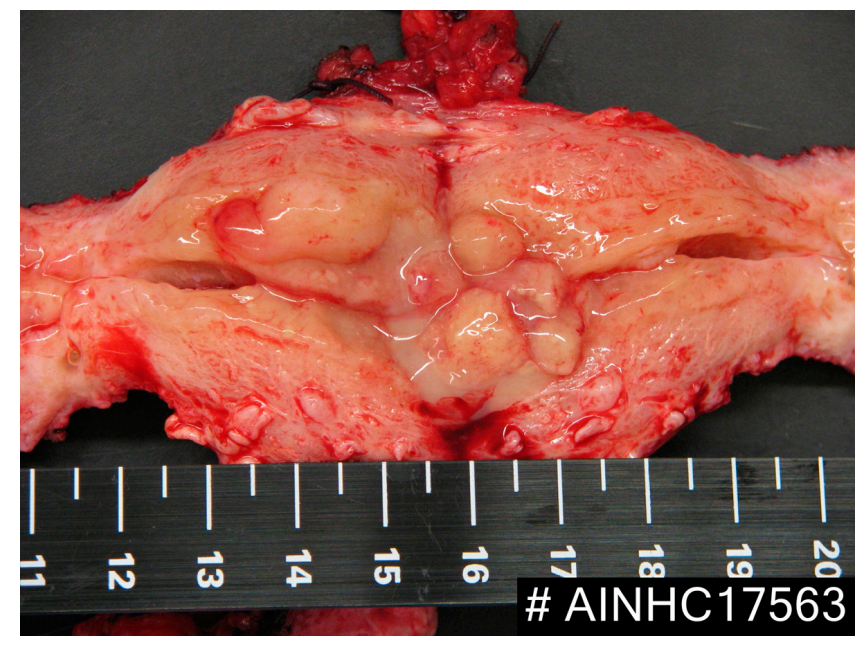

The final histological report identified the ovarian tumour as sertoliform adenoma from rete ovarii, with hepatocyte multifocal metaplasia, and a uterine $\mathrm{G} 2$ moderately differentiated endometrioid adenocarcinoma (FIGO staging IA, TNM staging T1aNOMO). (Figure 3-7).

Figure 3: Hematoxilin-eosin tinction from ovarian sample, showing adenomatose structures.

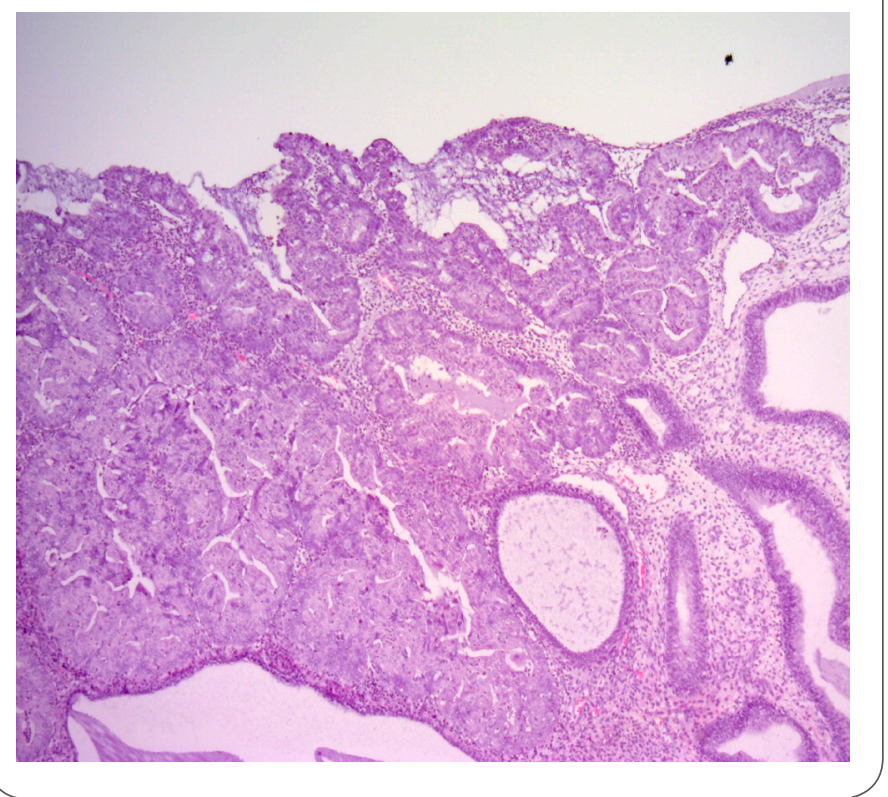

Figure 4: Leydig cells in ovarian sample.

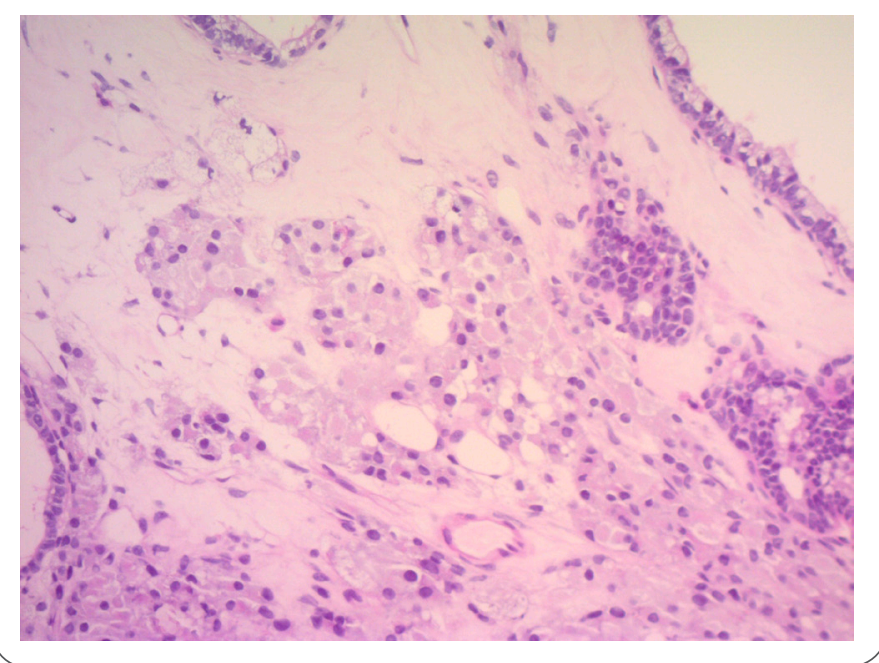


Figure 5: Hepatocytes in ovarian sample.

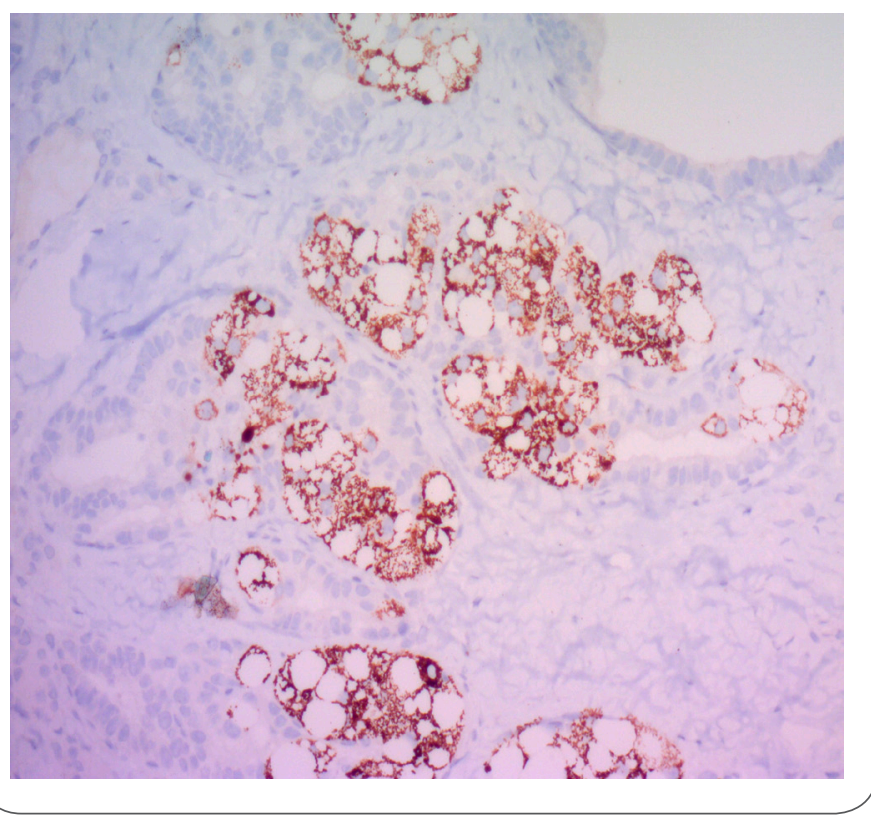

Figure 6: Alpha-Fetoprotein presence in ovarian sample.

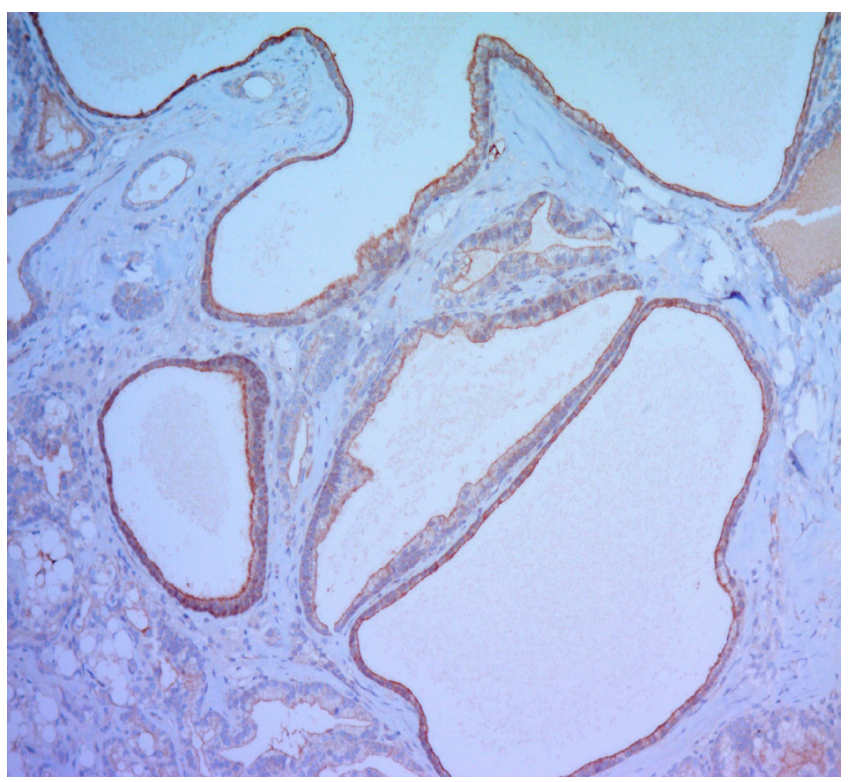

Figure 7: Presence of Inhibin in ovarian sample.

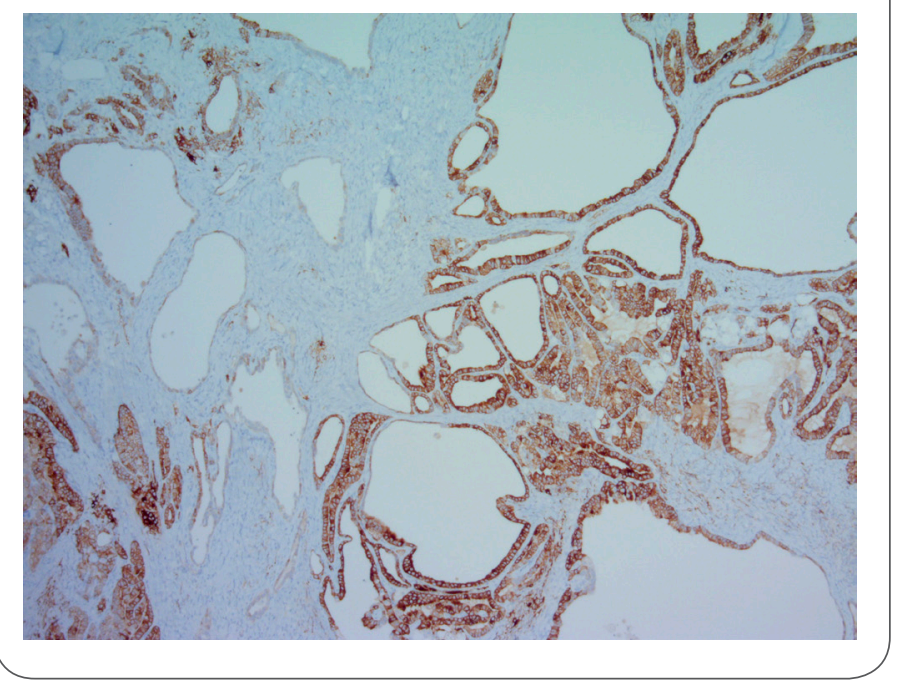

\section{Conclusions}

Sertoliform cystoadenoma is a very rare finding, with only a few cases reported, and it could be an estrogenic functioning tumour [7-11]. In other way, estrogenic overproduction has been related to endometrial hyperplasia and low malignancy degree endometrial neoplasms. In the present case, we suggest that endometrial carcinoma could be induced or related to the sertoliform cystoadenoma found in the ovary.

However, it could be a synchronous presentation without causal relationship between them [6].

The reported case has the particularity of containing hepatocyte multifocal metaplasia, not described in other reported cases. 


\section{References}

1. Young RH, Prat J, Scully RE: Ovarian endometrioid carcinomas resembling sex cord-stromal tumors: A clinicopathological analysis of 13 cases. Am J Surg Pathol 1982; 6: 513-22.

2. Young RH, Scully RE. Ovarian sex cord-stromal tumors: recent progress. Int J Gynecol Pathol. 1982; 1(1): 101-23.

3. Remadi S, Ismail A, Tawil A, Mac Gee W. Ovarian sertoliform endometrioid carcinoma. Virchows Arch 1995; 426: 533-6.

4. Young RH, Prat J, Scully RE: Ovarian Sertoli-Leydig cell tumors with heterologous elements. I. Gastrointestinal epithelium and carcinoid: a clinicopathologic analysis of thirty-six cases, Cancer. 1982, Dec 1; 50(11): 2448-56

5. Ordi J, Schammel DP, Rasekh L, Tavassoli FA: Sertoliform endometrioid carcinomas of the ovary: A clinicopathologic and immunohistochemical study of 13 cases. Mod Pathol 1999; 12: 933-40.

6. Irving JA, Catasus L, Gallardo A, Bussaglia E, Romero M X, J, Synchronous endometrioid carcinomas of the uterine corpus and ovary: alterations in the $\beta$-catenin (CTNNB1) pathway are associated with independent primary tumors and favorable prognosis, Human Pathology 2005, jun; 36(6): 605-19.

7. Suzuki M, Sekiguchi I, Tamada T: Estrogen production by epithelial ovarian tumors and dermoid cysts. Acta Obs Gynaec Jpn 1986; 38: 303-310.

8. Obata N, Sato Y, Tanaka K, Sasaki A, Takeuchi S, Hanaoka J, et al: Pathological and endocrinological study of epithelial ovarian tumors in postmenopausal women. Acta Obs Gynaec JPN 1986; 38: 647-656.

9. Ishikura $\mathrm{H}$, Sasano $\mathrm{H}$ : Histopathologic and Immunohistochemical study of steroidogenic cells in the stroma of ovarian tumors. Int J Gynecol Pathol 1986; 5: 19-337.

10. Rutgers JL, Scully RE: Functioning ovarian tumors with peripheral steroid cell proliferation: A report of twenty-four cases. Int J Gynecolo Pathol 1986; 5: 19-337.

11. Wren BG, Frampton J: Oestrogenic activity associated with non-feminizing ovarian tumours after the menopause. Br Med J 1963; 2: 842-844.

\section{Comment on this article:}

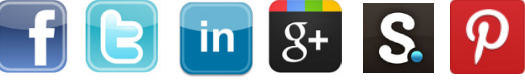

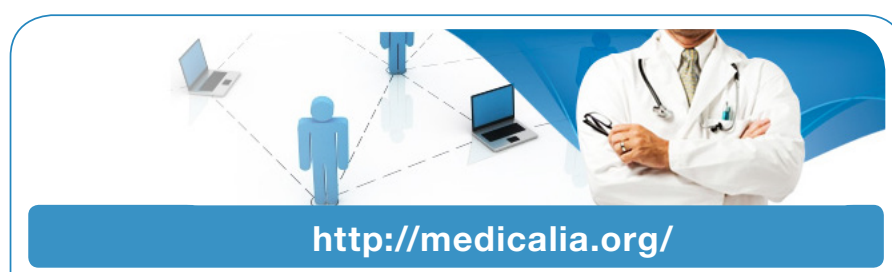

Where Doctors exchange clinical experiences, review their cases and share clinical knowledge. You can also access lots of medical publications for free. Join Now!

\section{Publish with iMedPub}

\section{http://www.imed.pub}

International Archives of Medicine is an open access journal publishing articles encompassing all aspects of medical science and clinical practice. IAM is considered a megajournal with independent sections on all areas of medicine. IAM is a really international journal with authors and board members from all around the world. The journal is widely indexed and classified Q1 in category Medicine. 